\title{
Principal Characters
}

Mílgroms

Ignáts Albértovich father

Anna Mikháilovna mother

Their five children:

Márya (Marúsya)

Márko

Lídiya (Líka)

Sergéi (Serézha)

Víktor (Tórik)

Abrám Moiséevich Mílgroms' relative

Borís Mavrikíevich (Béirish) Abrám's brother

Samóilo Kozodói Anna Mikháilovna's distant relative; pharmacist;

Marúsya's suitor

Alekséi Dmítrievich Runítsky (Alésha) Russian sailor in Volunteer

Navy; Marúsya's romantic interest

Nyúta attractive young woman

Nyúra her mother

Rovénsky her father 

THE FIVE

D.6\% - 
